\title{
Bilateral breast cancer and stomach metastasis: A Case Report
}

\section{Bilateral meme kanseri ve mide metastazı: Olgu sunumu}

\author{
Erdinç Nayır'1 ${ }^{1}$ Tolga Köșeci², Ali Arıcan ${ }^{3}$ \\ ${ }^{1}$ Kahramanmaraş Necip Fazıl Şehir Hastanesi, Tıbbi Onkoloji Kliniği, Kahramanmaraş, Türkiye \\ ${ }^{2}$ Numune Eğitim ve Araştırma Hastanesi, Tıbbi Onkoloji Kliniği, Adana, Türkiye \\ ${ }^{3}$ Acıbadem Atakent Hastanesi, Tıbbi Onkoloji Kliniği, İstanbul, Türkiye
}

Dergiye Ulaşma Tarihi: Dergiye Kabul Tarihi: 04/02/2016 DOI: 10.5505/aot.2016.74046

\section{ÖZET}

Meme kanseri kadınlarda en sık görülen kanserdir. Tüm meme kanserlerinin \%0,5-3’ü bilateral olarak görülmektedir. Meme kanserli hastalar genellikle erken evrede tanı almaktadır, yalnız metastatik dönemde de karşımıza çıkabilmektedir. Metastaz alanları genellikle kemik, akciğer ve karaciğerdir. Gastrointestinal sistemde metastaz nadir görülmekle birlikte sıklıkla kolon, rektum, mide ve özefagusa metastaz yapmaktadır. Kliniğimizde bilateral meme kanseri tanısıyla takip ettiğimiz ve tanı esnasında mide metastazı saptadığımız olguyu sizlere sunmayı amaçladık.

Anahtar Kelimeler: Bilateral meme kanseri, mide metastazı, senkron metastaz

\begin{abstract}
Breast cancer is the most commonly seen cancer in women. $0.5-3 \%$ of the all breast cancer cases occur bilaterally. Breast cancer is generally diagnosed in early stages, but it can be recognised in metastatic period. Most commonly seen metastasis sites are bone, lung and liver. Although metastasis in gastrointestinal system is rare; it may be seen in colon, rectum, stomach and esophagus. We aimed to present a woman who has the diagnosis of bilateral breast cancer and stomach metastasis at diagnosis.
\end{abstract}

Keywords: bilateral breast cancer, stomach metastasis, synchron metastasis

\section{Giriş:}

Meme kanseri kadınlarda en sık görülen kanserdir(1). Hastalar tanı anında genellikle erken evrededir. Meme kanseri s1klıkla lenf nodu akciğer, plevra ve karaciğere metastaz yapar (2). Gastrointestinal sisteme nadir olarak metastaz yapmakla birlikte sıklıkla kolon, rektum, mide ve özefagusa metastaz yapmaktadır (3). Bilateral meme kanseri görülme oran $1 \% 0,5-3$ arasındadır. Meme kanserinin mideye metastazı oldukça nadir olarak görülmekte olup bilateral meme kanseri ile eş zamanlı mide metastazı tanısı alan nadir olarak görülen bu olguyu sizlere sunmayı amaçladık.

\section{Olgu:}

52 yaşında kadın hastanın rutin sağlık kontrolleri sırasında her iki memesinde kitle saptand. Meme ultrasonografisinde sol memede yaklaşık $21 \times 14 \mathrm{~mm}$, să memede yaklaşık 30x17mm boyutunda solid lezyon görüldü. Sol memeden alınan biyopsi sonucu invaziv duktal karsinom, ER $\% 70$ pozitif, PR $\% 80$ pozitif, cerb-B2 negatif, e-cadherin pozitif tespit edildi. Să̆ memeden alınan biyopsi sonucu ise invaziv duktal karsinom, ER $\% 20$ pozitif, PR $\% 70$ pozitif, cerb-B2 negatif tespit edildi. Hastanın CA15-3 düzeyi $44 \mathrm{U} / \mathrm{mL}$, CEA düzeyi 1.76 ng/mL idi. 1 yıldır dispeptik şikâyetleri olan hastanın kanser evrelemesi için istenilen tomografisinde mide duvarında kalınlaşma 
saptand1. Yapılan üst gastrointestinal sistem endoskopisinde mide korpus pilileri hipertrofik, ödemli, dokunmakla frajildi ve nodüler lezyon izlendi. Alınan biyopside atipik hücre grupları görüldü. Meme karsinomu tanıs1 olması üzerine mide biyopsisinde immünohistokimyasal olarak östrojen, progesteron ve sitokeratin 7'ye bakıld1. Pozitif saptanması üzerine meme kanseri metastazı ile uyumlu olduğu düşünüldü. Kemik sintigrafisi ve SPECT'inde birden çok odakta kemik metastazı ile uyumlu görünüm saptandı. Metastatik bilateral meme kanseri tanısı konulan hastaya ibandronik asit başlandı ve 6 kür doksorubisin - siklofosfamid - dosetaksel kemoterapi rejimi uygulandi. Hastalığın stabil seyretmesi üzerine hormonal tedavi ile devam edilmektedir.

\section{Tartışma:}

Meme kanseri kadınlarda en sık olarak görülen kanserdir. Meme kanseri sıklıkla kemik, akciğer, karaciğer metastaz yapmakla birlikte mide, kolon, peritonada yayılım gösterebilir (2). Gastrointestinal sistemde en s1k metastaz yaptığ 1 bölgeler kolon, rektum, mide, ileum ve özefagustur (3). Yapılan postmortem çalışmalarında meme kanserinin mideye metastaz oranı \%2-18 oranında saptanmıştır (4).Meme kanserinin mideye metastazı genellikle tanı anından yıllar sonra görülmektedir. Sunduğumuz vakamızda ise meme kanseri ile eş zamanlı olarak açığa çıkmıştır. Mide metastazı olan meme kanserli hastalarda genellikle diğer organlarda da metastaz saptanmaktadır (5). Bizim vakamızda da iskelet sisteminde multipl metastatik lezyonlar saptandi.

Mideye metastaz yapmış olan meme kanserli hastaların kliniği primer mide kanseri tanısı almış hastaların kliniği ile benzerdir. Hastalar genellikle epigastrik bölgede şişkinlik, erken doyma, ağrı, kilo kaybı, kusma ve kanama şikâyeti ile başvururlar. Meme kanserinin mideye metastazı genellikle linitis plastika şeklinde olup nadiren de nodüler lezyonlar şeklinde olabilmektedir. İnvaziv lobuler karsinoma bağlı mide metastazın endoskopik bulgusu ülser, erezyon ya da polipoid lezyon olurken; invaziv duktal karsinoma bağl1 metastazlarda nodüler lezyon şeklinde görülmektedir (6). Bizim vakamızda ise hastamızın dispeptik yakınmaları mevcuttu ve yapılan endoskopisinde nodüler lezyon saptandı. Meme kanserinin en sik olarak görülen histopatolojik alt tipi invaziv duktal karsinom olup invaziv lobüler karsinom daha nadir olarak görülmektedir. Her iki alt tipinin öncelikle metastaz yaptığ 1 organlar farklılık göstermektedir. İnvaziv duktal karsinom daha çok akciğer, plevra ve kemiğe metastaz yaparken, invaziv lobuler karsinom ise kemik iliği ve peritona metastaz yapma eğilimindedir (7). Literatürde mide metastazı saptanan meme kanserli hastalarda histopatolojik alt tipin daha çok invaziv lobuler karsinom olduğu saptanmıştır. Taa ve arkadaşları 24 mide metastazı olan meme kanserli hastada yaptıkları histopatolojik alt tipi incelemesinde 20 hastada invaziv lobüler karsinom saptarken diğer hastalarda invaziv duktal karsinom olduğu gösterilmiştir (8).Bizim vakamızda ise saptanan histopatolojik alt tipi invaziv duktal karsinomdu.

Mide metastazı tanısını koyabilmek için lezyondan biyopsi alınıp, primer memedeki lezyon ile karşılaştırmalı olarak incelenmesi gerekmektedir. İnvaziv lobuler karsinomuna bağlı mide metastazlarının histopatolojik incelemesinde taşlı yüzük hücre görünümü saptanabilmektedir ve primer mide kanserinden ayırımı zor olabilmektedir. $\mathrm{Bu}$ nedenle bu hastalarda immünohistokimyasal boyama yöntemleri kullanılmalıdır. Östrojen ve progesteron reseptör pozitifliği meme kanserini düşündürmekle birlikte mide kanserli hastalarda 
da \%12-32 oranında östrojen ve progesteron reseptör pozitifliği olabileceği unutulmamalıdır (9). Bu hastalara mutlaka mamoglobulin ve GCDFP-15 bakılmalıdır. Eğer bu iki marker pozitif ise midedeki lezyonun meme kanseri metastazından kaynaklandığı gösterilmiş olur (10).

Meme kanseri tanısı almış bir kişide kontrolateral meme kanser açığa çıkma oranı $\% 0.5$ ile 3 arasında değişim göstermektedir. Primer lezyon ile eş zamanlı olarak açığa çıkarsa senkron eğer farklı bir zaman diliminde diğer memede kanser saptanırsa metakron olarak adlandırılır. Bizim vakamıda ise senkron bilateral meme kanseri mevcuttu (11). Bilateral meme kanseri olan hastalarda mide metastazı literatürde olgu sunumu şeklinde bulunmakta olup bu vakalarda mide metastazı hastalığın seyri esnasında açığa çıkmıştır. Bizim vakamızda ise mide metastazı, primer meme kanseri tanısıyla aynı dönemde tespit edilmiştir.

$\mathrm{Bu}$ hastaların tedavisinde sistemik kemoterapi ve hormon reseptör durumuna göre endokrin tedavi verilmesi önerilmektedir. Mide metastazına cerrahi müdahale yapılmasının sağkalıma katkısının olmadığı gösterilmiş olup sadece palyatif tedavi amaciyla cerrahi müdahale önerilmektedir. Mide metastazı olan meme kanserli hastalarda ortalama sağkalım yaklaşık olarak 2 yildır (6).

Sonuç olarak; meme kanseri tanısı alan hastalarda dispeptik yakınmalar eşlik ediyorsa mutlaka metastaz açısından değerlendirilmesi gerekmektedir. Mideden alınan biyopsi ile memedeki lezyondan alınan biyopsi mutlaka birlikte değerlendirilmelidir. $\mathrm{Bu}$ hastaların tedavisinde sistemik kemoterapi tedavisi önerilmektedir. Mide metastazı olan bilateral meme kanserli vaka sayısı literatürde birkaç olgu sunumu şeklinde bulunmakta olup bu vakalarda mide metastazı hastalığın takibi esnasında saptanmıştır. Bizim vakamız ise bilateral meme kanseri ile eş zamanlı mide metastazı olması açısından literatürde ilk vaka olarak yerini almaktadır.

Çıkar Çatışması: Yok

\section{Referanslar:}

1. Sakamoto G, Noguchi M, Inaji H, Hiraoka M, Kurosumi M, Itou Y. Disease of the breast. 1st ed. Tokyo: Kaneharasyuppann; 2006. p. 22-4.

2. Winston CB, Hadar O, Teitcher JB et al. Metastatic lobular carcinoma of the breast:Patterns of spread in the chest, abdomen and pelvis on CT.Am J Roentgenol2000; 175:795-800

3. Borst MJ, Ingold JA. Metastaticpatterns of invasive lobular versus invasive ductal carcinoma of the breast. Surgery. 1993; 114:637-41

4. Cormier WJ, Gaffey TA, Wech JM, Wech JS, Edmonson JH. Linitis plastica caused by metastatic lobular carcinoma of the breast. Mayo ClinProc1980;55:747-753

5. McLemore EC, Pockaj BA, Reynolds $\mathrm{C}$ et al. Breast cancer: presentation and intervention in women with gastrointestinal metastasis and carcinomatosis. AnnSurgOncol. 2005;12:886-94

6. Taal BG, Peterse $\mathrm{H}$, Boot $\mathrm{H}$. Clinical presentation, endoscopic features, and treatment of gastric metastases from breast carcinoma. Cancer2000;89:2214-21

7. Jain S, Fisher C, Smith P, Millis RR and Rubens RD. Patterns of metastatic breast cancer in relation to histological type. Eur J Cancer1993;29:2155-57

8. Hoff J, Portet R, Becue J, Fourtanier G, Bugat R. Digestive tract metastases of breast cancers. AnnChir1983;37:281-4

9. Raju U, Ma CK, Shaw A. Signet ring variant of lobular carcinoma of the breast: a clinicopathologic and immunohistochemical study. ModPathol. 1993;6:516-20.

10. Takeda Y, Tsuta K, Shibuki Y et al. Analysis of expression patterns of breas tcancerspecificmarkers (mammaglobin and gross cystic disease fluid protein15) in lung and pleural tumors. ArchPatholLabMed. 2008;132:239-43.

11. Banelli B, Casciano I, Di Vinci A. et al. Pathologica land molecular characteristics distinguishing contralateral metastatic from new primary breast cancer. Ann. Oncol. 2010;21:1237-42 